\title{
Imperfect Competition, Capital Shortages and Unemployment Persistence
}

\author{
Jean-Pascal Bénassy* \\ January 1995 \\ Revised April 1996 \\ $\mathrm{N}^{\circ} 9614$
}

Forthcoming, Scandinavian Journal of Economics

\footnotetext{
${ }^{*}$ I am most indebted to Franck Portier for his invaluable help with the simulations reported in this article, as well as for his comments on an earlier version of this paper. I also want to thank the referees of this Journal for their constructive comments. Of course I remain responsible for all remaining deficiencies.
} 


\title{
Imperfect competition, capital shortages and unemployment persistence
}

\begin{abstract}
We construct in this article a model integrating the traditions of Imperfect Competition Macroeconomics and Real Business Cycles. For this we study a dynamic economy with optimizing households, firms and trade unions subject to stochastic shocks. We can derive closed form solutions for the behavior of all agents. It is found that the combination of capital shortages and imperfect competition in labor markets can give rise to unemployment, and that this unemployment is quite persistent, even when the underlying shocks are not.
\end{abstract}

J.E.L. codes : E32

Keywords : Unemployment persistence, cycles, imperfect competition

\section{Concurrence imparfaite, insuffisance de capital et persistance du chômage}

\section{RESUME}

On construit dans cet article un modèle synthétisant la tradition de la macroéconomie de la concurrence imparfaite et celle des "cycles réels". Pour cela on étudie une économie soumise à des chocs stochastiques où entreprises, ménages et syndicats optimisent dans un cadre intertemporel. On obtient des solutions exactes décrivant le comportement optimal de tous les agents. Celles-ci permettent de montrer que la combinaison de concurrence imparfaite sur les marchés du travail et d'une insuffisance de capital engendre du chômage et que ce chômage est extrêmement persistant, même quand les chocs sous-jacents ne le sont pas.

Codes J.E.L. : E.32

Mots Clés : Persistance du chômage, cycles 


\section{Introduction}

The purpose of this article is to construct a model integrating the traditions of Imperfect Competition Macroeconomics (ICM) and Real Business Cycles (RBC) by studying a dynamic economy with optimizing households, firms and trade-unions subject to stochastic shocks. We shall investigate with the help of that model the hypothesis that capital shortages combined with imperfect competition in the labor market can lead to persistent unemployment.

The integration of the two above traditions is actually quite timely. Researchers working in the area of imperfect competition macroeconomics have started for some time building explicitly dynamic models (see notably Silvestre, 1995, for a recent survey). On the other hand a few authors in the $\mathrm{RBC}$ line have felt the necessity of including some elements of imperfect competition in their models (e.g. Darithine and Donaldson, 1999, 1992, Hairault and Portier, 1993, Rotemberg and Woodford, 1992). In fact the introduction of imperfect competition in the RBC line is a logical prerequisite if one wants to study such a fundamental problem as unemployment ${ }^{1}$ and its fluctuations, which Walrasian models cannot tackle by definition. We shall actually show that our imperfectly competitive model allows to reproduce several features that traditional RBC contributions have had difficulties to capture, such as high fluctuations and persistence in unemployment, or persistence in output beyond that deriving from persistence in the shocks.

The particular mechanism leading to this persistence is based on the idea, developed notably in Burda (1988), that the recent high and persistent unemployment observed particularly in Europe might have been caused by insufficient capital accumulation combined with imperfect competition in the labor market ${ }^{2}$. This has also been studied under various forms by several authors (Bean, 1989, Hénin and Jobert, 1993, Sneessens, 1987, Van de Klundert and Von Schaik, 1990). The theoretical analyses were mostly deterministic, however, and by introducing stochastic shocks as in the RBC literature we

\footnotetext{
${ }^{1}$ Unemployment meaning here the existence of agents unable to find as much work as they supply.

${ }^{2}$ Drèze and Bean (1990) contains a number of interesting country studies aiming, in particular, to ascertain the role of "capital shortages" in recent european unemployment.
} 
can study explicitly the issues of fluctuations and persistence.

Imperfect competition in the labor market will be introduced in the simplest possible manner, as we shall make the traditional assumption that wages are set in each firm by a "monopoly union" 3 . The persistence mechanism can now be intuitively described as follows: Under limited capital-labor substitutability and wage setting by a monopoly union, insufficient capital leads to low employment. Moreover low capital and low employment lead to low accumulation, hence low capital and low employment next period. The mechanism therefore produces persistence in all variables, including unemployment.

A quite important feature of the model we shall develop is that, although the maximization problems are stochastic and nonlinear, we shall be able to derive closed form solutions for the behavior of households, firms and trade unions, which will make the analysis and results more transparent than in purely numerically calibrated models.

\section{The Model}

In order to obtain closed form solutions, we shall consider here a dynamic model based on that by Huffman (1993), with firms and overlapping generations of households with stochastic lives. Technology is submitted to random shocks as in the RBC models of Kydland-Prescott (1982) and Long-Plosser (1983). Imperfect competition will be brought in as wages will be fixed by firm specific trade unions.

The economy is populated with a continuum of representative firms and households. To make notation simpler, and since everything will be "proportional", we shall use the same notation for aggregate variables and the variables concerning representative agents.

\footnotetext{
${ }^{3}$ Clearly the argument could be extended to a more general wage-setting scheme where the level of wages would be bargained between each firm and trade-union, while the firm would retain full decision on the employment level. See for example Jacobsen and Schultz (1994) for such a model and the consequences on employment in a deterministic rational expectations framework.
} 


\section{Firms}

Firms have a production function:

$$
Y_{t}=Z_{t} F\left(K_{t}, L_{t}\right)
$$

where $Y_{t}$ is output, $K_{t}$ capital available to the firm in period $t, L_{t}$ the quantity of labor used and $Z_{t}$ a technological shock common to all firms. $F$ is homogeneous of degree one, and we shall denote by $\sigma(L / K)$ the elasticity of substitution between labor and capital, i.e.

$$
\sigma(L / K)=-\frac{\partial \log (L / K)}{\partial \log \left(F_{L} / F_{K}\right)}
$$

We shall assume below a limited substitutability between factors, and more specifically that $\sigma(L / K)$ is strictly smaller than one. As an illustration, with a C.E.S. production function of the form:

$$
Y_{t}=Z_{t}\left(a K_{t}^{\alpha}+b L_{t}^{\alpha}\right)^{1 / \alpha}
$$

the elasticity of substitution $\sigma(L / K)$ is constant and equal to $\sigma$, where:

$$
\sigma=\frac{1}{1-\alpha}
$$

and the assumption $\sigma<1$ will be then equivalent to $\alpha<0$.

Firms are price takers on all markets and thus consider the price $P_{t}$ and wage $W_{t}$ as exogenous to them.

\section{Households}

There is a continuum of households. The population size $N$ will be normalized to 1 . The preferences of all households alive at date $t$ are represented by the utility function:

$$
E\left[\sum_{s=t}^{\infty} \beta^{s-t} \log C_{s}\right] \quad 0<\beta<1
$$


At each date all alive households have a uniform probability of dying $\gamma$. We assume a constant population so that $\gamma N$ households actually disappear each period and $\gamma N$ new ones enter the economy. New entrants in the economy are endowed in the first period of their life with a quantity of labor which they supply inelastically. We shall denote by $L_{0}$ the aggregate labor supply. Households will thus receive labor income in their first period, and will thereafter save under the form of capital for future consumptions. We assume that households learn at the beginning of each period whether they will be alive next period, so that only "survivors" will actually save and carry capital to the next period.

\section{Trade unions}

In each period households working in a firm form a trade union which aims at maximizing the expected utility of the representative worker in the firm. This is a traditional "monopolistic" trade union, which sets unilaterally the wage, leaving to the firm the right to choose the level of employment. We assume that by an adequate redistribution scheme all workers in the firm have the same income. Then the trade union will be led quite naturally to maximize the real value of labor income in period $t$, i.e. to maximize $W_{t} L_{t} / P_{t}$

\section{Resolution}

\section{Households}

With a probability of death $\gamma$ in each period, maximization of utility function (5) is equivalent (for a surviving household) to maximizing the expectation of:

$$
\sum_{s=t}^{\infty} \beta^{s-t}(1-\gamma)^{s-t} \log C_{s}+\sum_{s=t+1}^{\infty} \beta^{s-t} \gamma(1-\gamma)^{s-t-1} \log C_{s}^{\prime}
$$

subject to the budget constraints: 


$$
\begin{gathered}
C_{s}+K_{s}=\kappa_{s} K_{s-1} \\
C_{s}^{\prime}=\kappa_{s} K_{s-1}
\end{gathered}
$$

where $\kappa_{s}$ is the return in period $s$ on capital invested the previous period, $C_{s}$ is consumption in $s$ for a household who will survive, $C_{s}^{\prime}$ for a household who will disappear at the end of the period. The first order conditions for this dynamic program yield:

$$
\frac{K_{s}}{C_{s}}=\beta \gamma+\beta(1-\gamma) E_{s}\left(\frac{C_{s+1}+K_{s+1}}{C_{s+1}}\right)
$$

whose solution is a constant consumption savings ratio in all periods:

$$
\frac{K_{s}}{C_{s}}=\frac{\beta}{1-\beta+\beta \gamma}
$$

This means that "survivors", who are in proportion $1-\gamma$ in the population, save a fraction $\beta /(1+\beta \gamma)$ of their real income. Since the proportion $\gamma$ of households who will disappear save nothing, the aggregate propensity to save is $\beta(1-\gamma) /(1+\beta \gamma)$.

Now we assume that a fraction $\delta$ of capital depreciates each period. Total income is thus equal to $Y_{t}+(1-\delta) K_{t}$ (wages plus profits plus undepreciated capital), so that aggregate household behavior is summarized by:

$$
\begin{gathered}
K_{t+1}=\frac{\beta(1-\gamma)}{1+\beta \gamma}\left[Y_{t}+(1-\delta) K_{t}\right] \\
C_{t}=\frac{1-\beta+2 \beta \gamma}{1+\beta \gamma}\left[Y_{t}+(1-\delta) K_{t}\right]
\end{gathered}
$$

\section{Firms}

The representative firm has an amount of capital $K_{t}$ at time $t$. Being a wage and price taker, it maximizes profit for given $K_{t}, W_{t}$ and $P_{t}$, which yields a demand for labor given by: 


$$
Z_{t} F_{L}\left(K_{t}, L_{t}\right)=\frac{W_{t}}{P_{t}}
$$

\section{Trade unions}

In period $t$ the representative trade union chooses the real wage $W_{t} / P_{t}$ so as to maximize $W_{t} L_{t} / P_{t}$. Clearly it will never choose a wage such that the demand for labor, as given by (8), is higher than the supply $L_{0}$, as otherwise it could increase $W_{t} / P_{t}$ without lowering $L_{t}$. Therefore equality (8) will always hold and the program of the trade union is thus, for a given level of capital in the firm (note that the multiplicative factor $Z_{t}$ drops out):

$$
\text { Maximize } L_{t} F_{L}\left(K_{t}, L_{t}\right) \text { s.t. } \quad L_{t} \leq L_{0}
$$

The function $L F_{L}(K, L)$ is plotted in Figure 1 for a given level of $K$ and assuming that the elasticity of substitution is strictly smaller than 1 :

$$
\sigma(L, K) \leq \hat{\sigma}<1
$$

\section{Figure 1}

Under assumption (9), $L F_{L}$ has at least one maximum characterized by:

$$
\frac{\partial}{\partial L}\left[L F_{L}(K, L)\right]=0
$$

We shall assume that the function $L F_{L}(K, L)$ is strictly quasi-concave in $L$ (for example this is the case for all C.E.S. functions with $\sigma<1$ ) and thus that equation (10) defines a unique maximum. Because $F$ is homogeneous of degree one in its arguments, this maximum is characterized by a fixed ratio $L / K$, which will be denoted by $\mu$. The trade union's wage employment strategy is therefore defined by the following equations:

$$
\begin{aligned}
L_{t} & =\min \left(\mu K_{t}, L_{0}\right) \\
\frac{W_{t}}{P_{t}} & =Z_{t} F_{L}\left(K_{t}, L_{t}\right)
\end{aligned}
$$




\section{The two regimes, dynamics and persistence}

The dynamics of the model can be briefly summarized by putting together equations (1), (6) and (11), which we recall here:

$$
\begin{gathered}
L_{t}=\min \left(\mu K_{t}, L_{0}\right) \\
Y_{t}=Z_{t} F\left(K_{t}, L_{t}\right) \\
K_{t+1}=\frac{\beta(1-\gamma)}{1+\beta \gamma}\left[Y_{t}+(1-\delta) K_{t}\right]
\end{gathered}
$$

The variables $K, L$ and $Y$ evolve thus according to nonlinear stochastic dynamic equations. To get an intuitive grasp of it, we can picture the evolution of capital (which is the state variable) for a constant value of the technological parameter $Z$, which is done in figure 2 for the central value $Z=1$.

\section{Figure 2}

Because of equation (11), the dynamics display two clearcut regimes with markedly different properties. The first regime corresponds to full employment $\left(L_{t}=L_{0}\right)$. There the model behaves as the Wairasian counterpart, which not only produces no unemployment, but also little persistence in output, as will appear below in the simulations.

In the unemployment regime $\left(L_{t}=\mu K_{t}\right)$ things change drastically. Indeed combining the three equations above we obtain:

$$
\begin{gathered}
K_{t+1}=\frac{\beta(1-\gamma)}{1+\beta \gamma}\left[1-\delta+Z_{t} F(1, \mu)\right] K_{t} \\
L_{t}=\mu K_{t}
\end{gathered}
$$


Call $k_{t}, \ell_{t}$ and $z_{t}$ the logarithms of $K_{t}, L_{t}$ and $Z_{t}$. Loglinearizing the first equation around the central value $z_{t}=0$, we obtain the following dynamics in $k_{t}$ and $\ell_{t}$ :

$$
\begin{gathered}
k_{t+1}=k_{t}+\phi z_{t}+\theta \\
\ell_{t}=k_{t}+\log \mu
\end{gathered}
$$

with:

$$
\begin{gathered}
\phi=\frac{F(1, \mu)}{1-\delta+F(1, \mu)} \\
\theta=\log \left[\frac{\beta(1-\gamma)}{1+\beta \gamma}\right]+\log [1-\delta+F(1, \mu)]
\end{gathered}
$$

We see that there is a large amount of persistence. Indeed, if $z_{t}$ is a white noise, then $k_{t}$ and $\ell_{t}$ will follow a random walk with drift in that regime!

Of course the system will switch from one regime to the other and the actual dynamics will be some complex combination of the "Walrasian" and "unemployment" dynamics. The above calculations suggest that, as soon as shocks are strong enough to bring the economy in the unemployment regime ${ }^{4}$, we will observe much more persistence than in the corresponding Walrasian economy. This cannot be studied analytically because of the nonlinearities, so we shall use simulations based on a simple example.

\section{Numerical simulations}

We shall now work out the case of the C.E.S. production function (3) seen above:

$$
Y_{t}=Z_{t}\left(a K_{t}^{\alpha}+b L_{t}^{\alpha}\right)^{1 / \alpha} \quad \alpha<0
$$

In that case it is easy to compute:

\footnotetext{
${ }^{4}$ Note that this requires shocks of some minimal amplitude since, in the absence of shocks, the "long run equilibrium" would be in the interior of the Walrasian regime (see figure 2).
} 


$$
\mu=\left(\frac{-\alpha a}{b}\right)^{1 / \alpha}
$$

We simulate the dynamic effects of simple autoregressive technological shocks of the form:

$$
z_{t}=\nu z_{t-1}+\epsilon_{t}
$$

where the variables $\epsilon_{t}$ are i.i.d.. The reader should be warned that the model has not be subject to any kind of "calibration" or estimation, so that the results that follow are simply meant to show that the intuitions about persistence that can be derived from equations such as (13) and (14) are actually supported by numerical experiments.

\section{Impulse response functions}

A first exercise consists in studying the impulse response functions of shocks, i.e. the dynamic response to a one time shock on $\epsilon_{t}$. An example of such response functions for output is depicted in Figure 3, which corresponds to full depreciation $(\delta=0)$ and an autoregressive shock $(\nu=0.5)$. Two things appear quite clearly on this graph (the upper curve corresponds to a positive shock, the lower one to a negative shock of the same magnitude):

- The first obvious thing is the asymmetry between the effects of positive and negative shocks: negative shocks yield "stronger" effects than positive ones as unemployment occurs.

- Secondly, in the case of a large enough negative shock, we observe some kind of "persistence", in the sense that unemployment decreases slowly and as a consequence the return of output to its steady state value is quite delayed as compared to the full employment case.

\section{Figure 3}


output IRF to a $\mathrm{z}$ shock

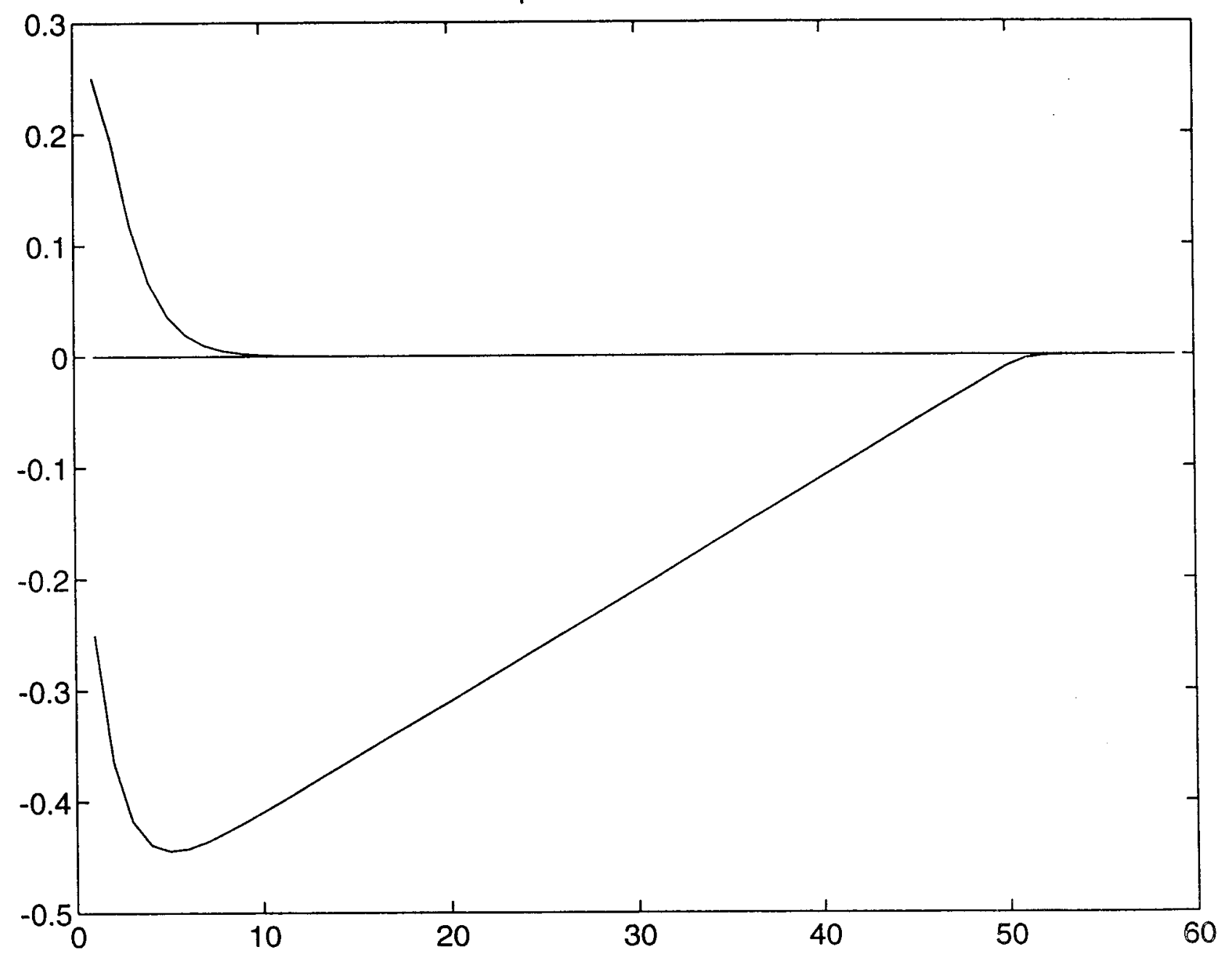

Figure 3 


\section{Fluctuations and persistence}

In order to show the potentiality of this imperfectly competitive model to generate actual persistence (i.e. persistence in some statistical sense) in unemployment and other variables, we have run simulations in the case least likely to produce persistence in capital (and thus employment), that where capital fully depreciates each period $(\delta=1)$. In that case, while equation (14) remains fully valid, the loglinear approximation (13) becomes the following exact formula:

$$
k_{t+1}=k_{t}+z_{t}+\theta
$$

Some of the results of various simulations are pictured in Figures 4 and 5. These simulations tell us a number of important things.

First the autocorrelations for employment and unemployment ${ }^{5}$ are displayed in Figure 4 in the case of i.i.d. shocks $(\nu=0)$. We see that the mechanism we studied produces large persistence in both employment and unemployment, even when the underlying shocks are totally uncorrelated, something that traditional RBC models largely fail to obtain. Other simulations show that these autocorrelations still increase as shocks become more persistent.

Figure 5 displays the output autocorrelations (in logarithms) for both our imperfectly competitive model (continuous lines) and the corresponding Walrasian model (dotted lines). Figure 5a corresponds to i.i.d. shocks $(\nu=0)$ and Figure 5b to autocorrelated shocks $(\nu=0.5)$. In both cases it appears most clearly that the introduction of imperfect competition dramatically increases the persistence of output, whether the underlying shocks are correlated or not.

\section{Figure 4}

\footnotetext{
${ }^{5}$ Because labor supply is constant here, autocorrelations between the absolute values of employment and unemployment are the same. But we purposefully distinguish between the two in the text as they would usually differ, for example with a variable labor supply or if, as in Walrasian models, unemployment was identically zero.
} 


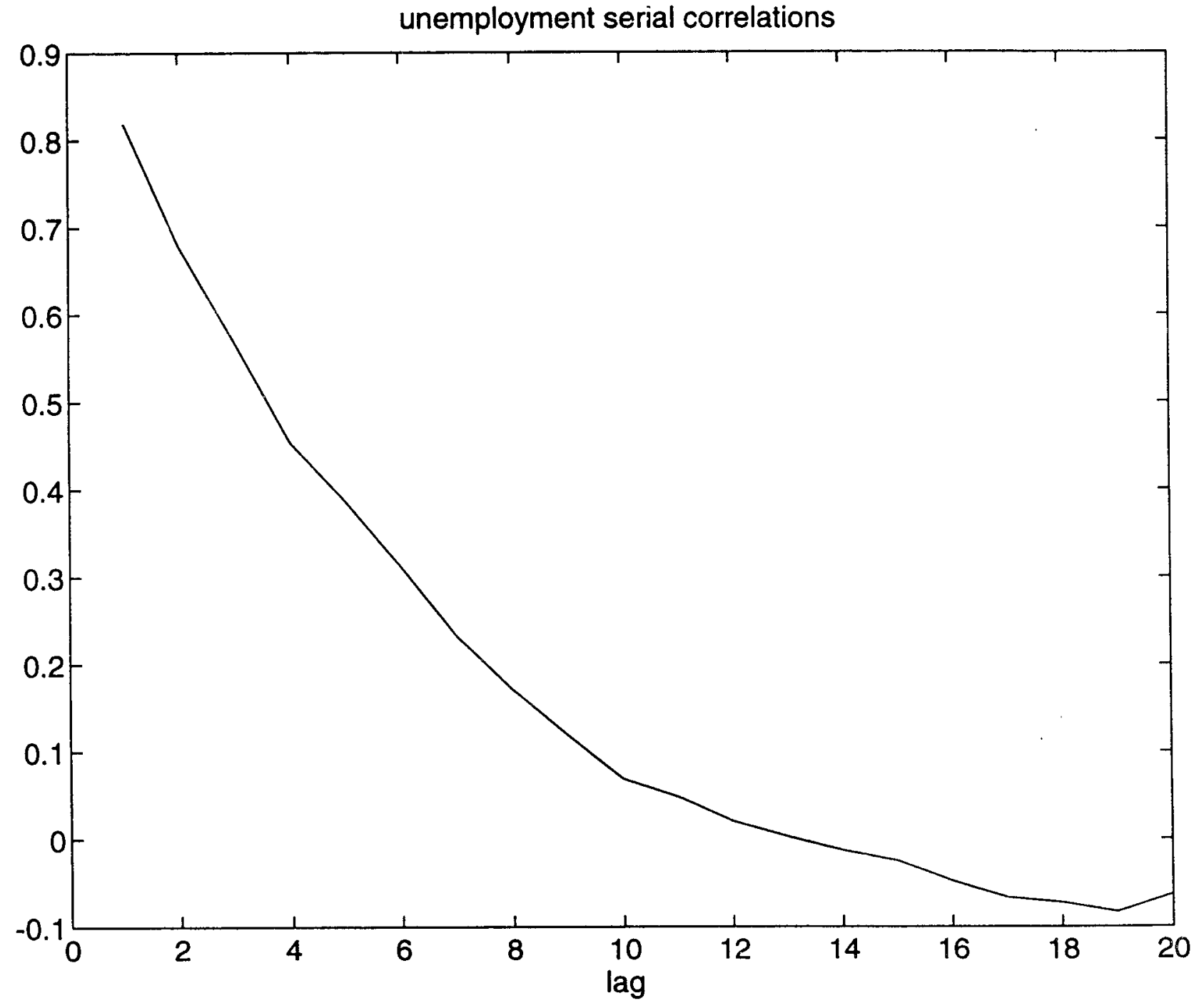

FIGURE 4 


\section{Figure 5}

\section{Conclusions}

We constructed in this paper a rigorous dynamic model of an imperfectly competitive economy subject to technology shocks. A closed form solution was obtained, yielding nonlinear stochastic evolutions. A study of this dynamic system shows that insufficient capital accumulation combined with imperfect competition on the labor market can yield unemployment, and that this unemployment can be highly persistent, even if the underlying shocks are not. Output is similarly found to be much more persistent than in the corresponding Walrasian economy. Also it was found in the simulations that employment and unemployment are much more variable than in traditional RBC models. Finally the system displays an interesting asymmetry due to the existence of two well distinct regimes. All these results are particularly promising, and should encourage us to pursue further this line of work.

We may note at this stage that the model presented in this article is very much "supply side oriented": only technology shocks are considered and employment is essentially influenced by supply side elements, following closely either labor supply (in the full employment regime) or the level of capital (in the unemployment regime). A natural development, among several others, could thus be to introduce demand elements in various ways: A first one would be to have a formalization of markets allowing for "demand determined" regimes as well. The second would be to introduce demand shocks in addition to supply shocks. Such additions should be the object of further reseach. 


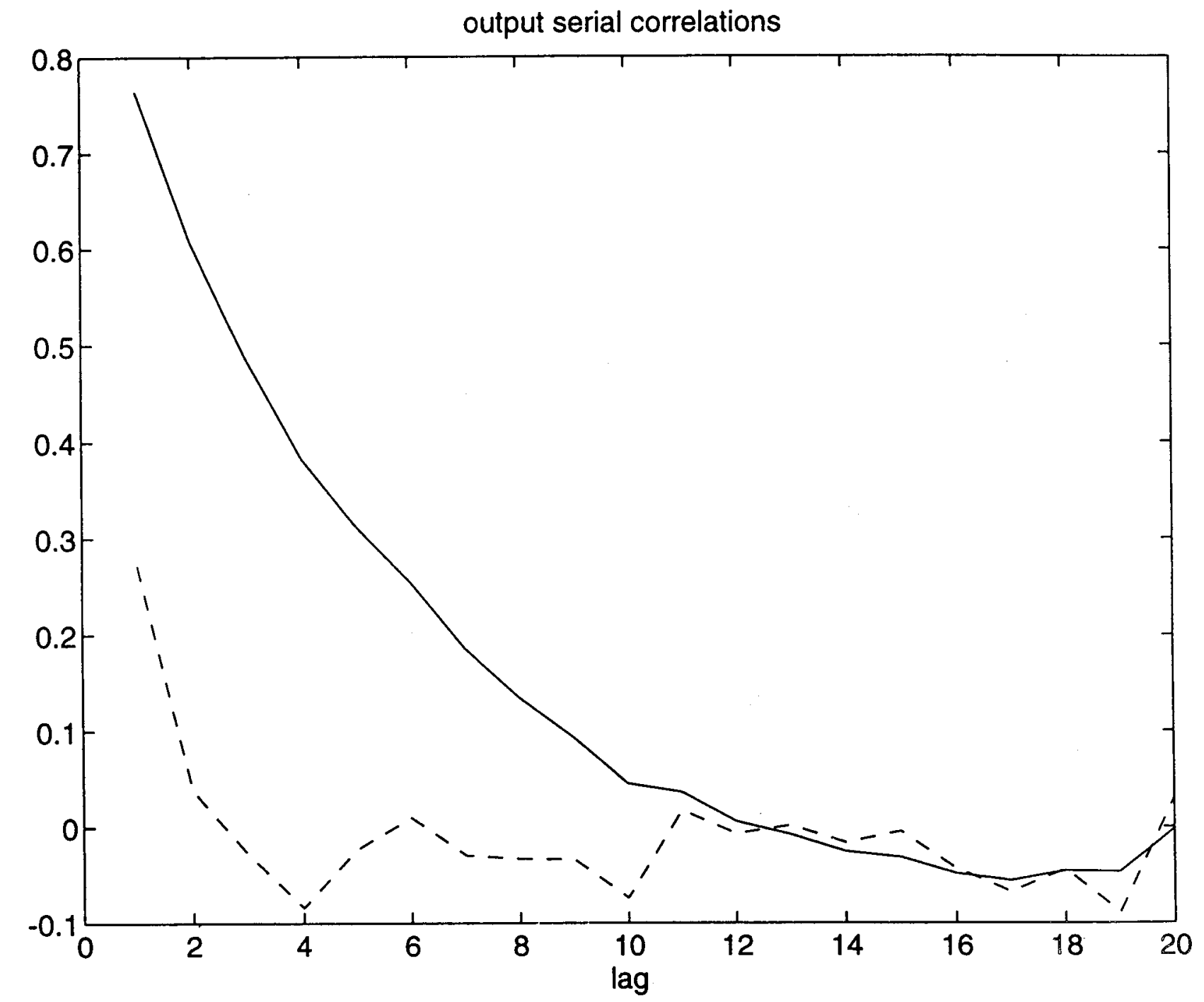

Figure $5 a$ 


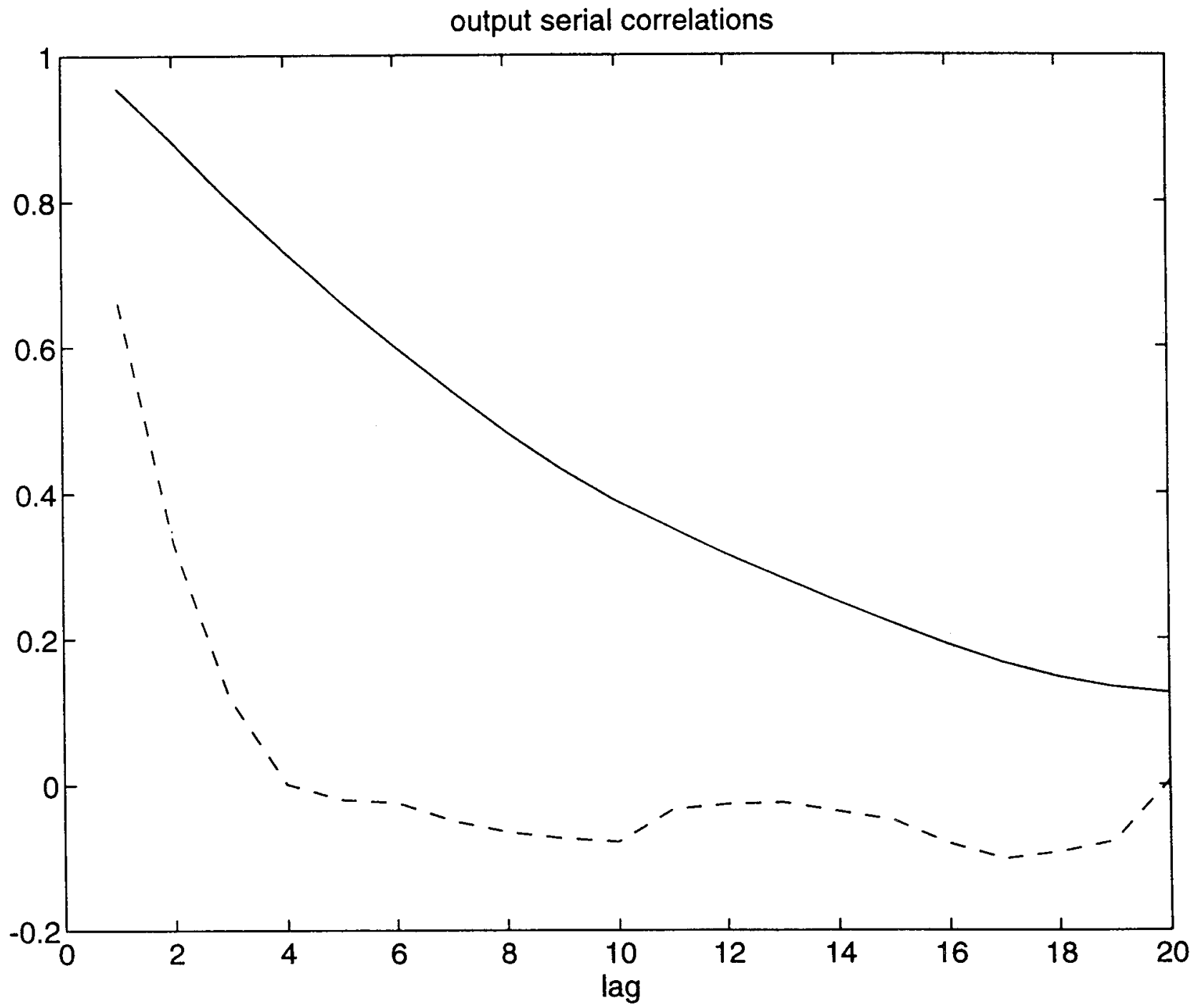

Figure 5 b 


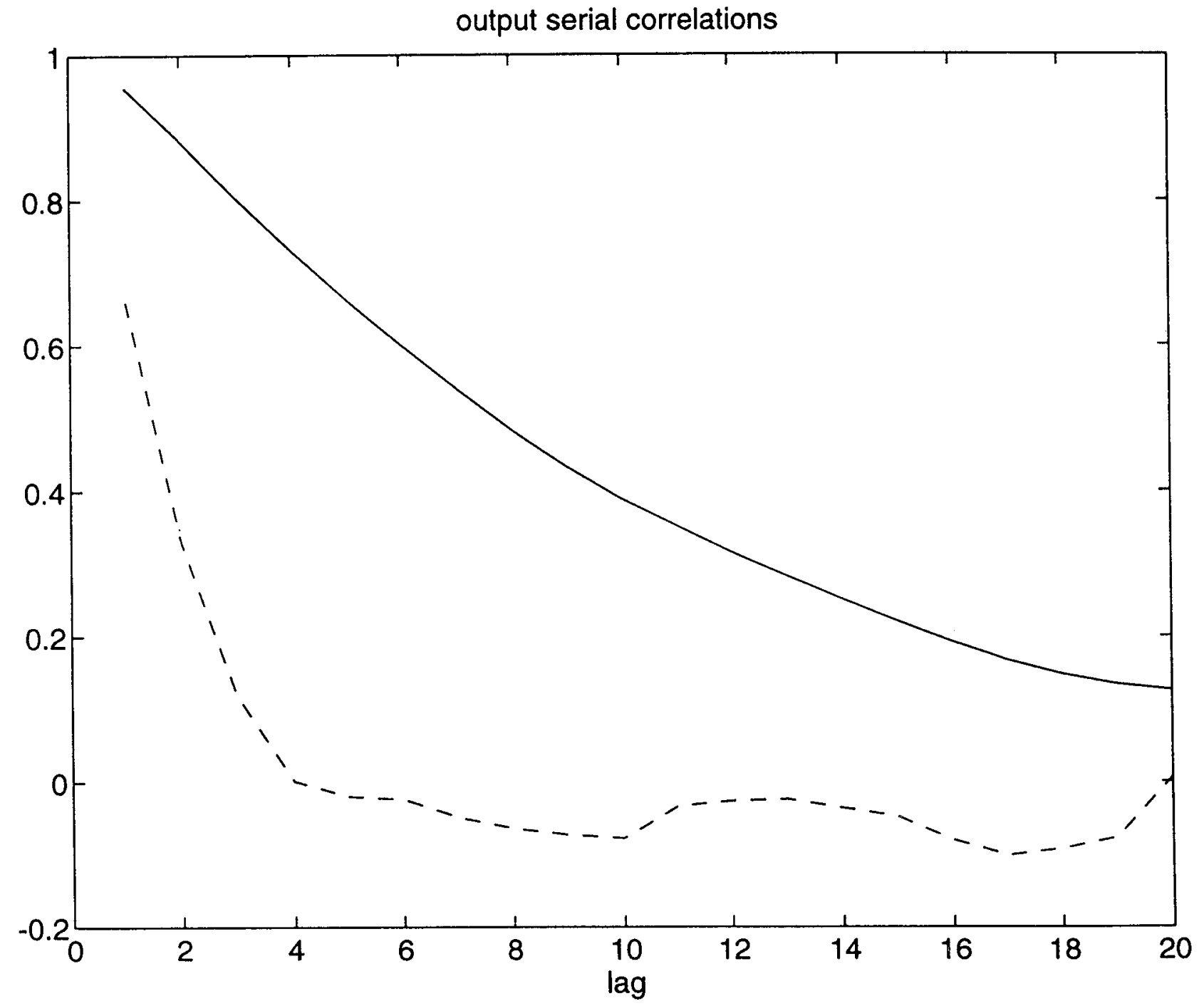

Figure 5 b 


\section{References}

[1] BEAN, Charles (1989), "Capital shortages and persistent unemployment", Economic Policy, no 8, pp 11-53.

[2] BURDA, Michael C. (1988), "Is There a Capital Shortage in Europe?", Weltwirtschaftliches Archiv, vol. 124, pp 38-57.

[3] DANTHINE, Jean-Pierre and DONALDSON, John B. (1990), " Efficiency wages and the business cycle puzzle", European Economic Review, vol. 34, pp 1275-1301.

[4] DANTHINE, Jean-Pierre and DONALDSON, John B. (1992), "Risk sharing in the business cycle", European Economic Review, vol. 36, pp $468-475$.

[5] DREZE, Jacques H. and BEAN, Charles R. (1990), Europe's Unemployment Problem, The M.I.T. Press, Cambridge, Mass.

[6] HAIRAULT, Jean-Olivier and PORTIER, Franck (1993), "Money, newKeynesian macroeconomics and the business cycle", European Economic Review, vol. 37, pp 1533-1568.

[7] HENIN, Pierre-Yves and JOBERT, Thomas (1993), "Profits, investissement et chomage", in Pierre-Yves Hénin (ed), La persistance du chomage, Economica, Paris.

[8] HUFFMAN, Gregory W. (1993) "An alternative neo-classical growth model with closed-form decisions rules", Economics Letters, vol. 42, pp 59-63.

[9] JACOBSEN, Hans-Jorgen and SCHULTZ, Christian (1994), "On the effectiveness of economic policy when competition is imperfect and expectations rational", European Economic Review, vol. 38, pp 305-327

[10] KYDLAND, Finn E. and PRESCOTT, Edward (1982), "Time to build and Aggregate Fluctuations", Econometrica, vol. 50, pp 1345-1370. 
[11] LONG, John B. and PLOSSER, Charles I. (1983), "Real Business Cycles", Journal of Political Economy, vol. 91, pp 39-69.

[12] ROTEMBERG, Julio and WOODFORD, Michael (1992), "Oligopolistic Pricing and the Effects of Aggregate Demand on Economic Activity", Journal of Political Economy, vol. 100, pp 1153-1207.

[13] SILVESTRE, Joaquim (1995), "Market Power in Macroeconomic Models: New Developments", Annales d'Economie et de Statistique, vol. 37-38, pp 319-356.

[14] SNEESSENS, Henri R. (1987), "Investment and the inflationunemployment tradeoff in a macroeconomic rationing model with monopolistic competition", European Economic Review, vol. 31, pp 781808 .

[15] VAN DE KLUNDERT, Theo C.M.J. and VON SCHAIK, Anton B.T.M. (1990), "Unemployment Persistence and Loss of Productive Capacity: A Keynesian Approach", Journal of Macroeconomics, vol. 12, pp 363-380. 